\title{
HIV medicine
}

\section{Cytomegalovirus retinitis in patients with acquired immune deficiency syndrome}

\author{
K G Au Eong, S Beatty, S J Charles
}

\begin{abstract}
Summary
Cytomegalovirus (CMV) retinitis is the most common intra-ocular infection in patients with acquired immune deficiency syndrome (AIDS), and a leading cause of AIDS-related morbidity. Untreated CMV retinitis in AIDS patients is a progressive and potentially blinding disorder. The diagnosis of CMV retinitis is a clinical one and it is important for physicians to be familiar with the clinical features of the disease. Ophthalmic screening of AIDS sufferers should be undertaken at regular intervals, and this is dictated, in part, by the patient's CD4+ T-lymphocyte (CD4) counts. CMV retinitis may be treated with systemic ganciclovir, foscarnet or cidofovir, or with local (intravitreal) therapy. CMVrelated retinal detachment is treated surgically. In some patients with quiescent $\mathrm{CMV}$ retinitis receiving highly active antiretroviral therapy, anti-CMV maintenance therapy may be discontinued in favour of close ophthalmologic observation and CD4 count monitoring.
\end{abstract}

Keywords: AIDS; cytomegalovirus retinopathy; ocular infection

Department of Ophthalmology, University of Manchester, Manchester, UK

K G Au Eong

S Beatty

Manchester Royal Eye Hospital, Manchester, UK

S J Charles

Correspondence to Mr KG Au Eong, Department of Ophthalmology, University of Manchester, Royal Eye Hospital, Oxford Road, Manchester M13 9WH, UK

Accepted 28 April 1999
Infection with cytomegalovirus (CMV), an ubiquitous member of the herpes group of viruses, is very common among the general population (box 1). ${ }^{1}$ Serological studies indicate that previous exposure to CMV has occurred in a large proportion of adults throughout the world, and although the rates vary depending on the population studied, up to $90 \%$ of middle-aged adults may have been exposed. In most cases, CMV does not cause clinically apparent disease. CMV infection of the eye, however, is seen in immunocompromised individuals such as patients with acquired immune deficiency syndrome (AIDS), those with organ transplant on immunosuppressive drugs, and in congenitally infected newborns. ${ }^{12} \mathrm{CMV}$ retinitis is more common in AIDS patients than in organ or bone marrow transplant recipients.

\section{Epidemiology}

The first cases of CMV retinitis in AIDS patients were reported in $1982 .{ }^{3}{ }^{4}$ It is now recognised as the most common retinal infection in patients with AIDS (table 1). ${ }^{5}$ It tends to occur late in the course of the disease, and is associated with peripheral blood absolute CD4+ T-lymphocyte (CD4) counts below 50 cells/ $\mu$ l (box 2). Kuppermann and associates found that $30 \%$ of their patients with CD 4 counts of less than 50 cells/ $\mu$ l had CMV retinitis. ${ }^{7}$ Although CMV retinitis may occasionally be seen in a patient with a CD4 count in excess of 200 cells $/ \mu \mathrm{l}$, this is not typical, and other causes of necrotising retinitis, including toxoplasmic retinochoroiditis, should be considered in the differential diagnosis. CMV retinitis may, on rare occasions, be the presenting sign of symptomatic human immunodeficiency virus (HIV) infection. ${ }^{8-10}$

\section{Clinical features}

SYMPTOMS

The symptoms of CMV retinitis depend on its initial location. Visual symptoms of peripheral lesions include floaters and loss of peripheral vision, but not all patients are symptomatic. ${ }^{7}$ More posteriorly located lesions result in paracentral or central scotomas. The visual loss in CMV retinitis is usually the result of retinal necrosis, but macular oedema secondary to retinitis near the macula may also reduce visual acuity. Other mechanisms which may be involved in loss of central or peripheral vision in this condition include retinal detachment and CMV papillitis.

Table 1 Prevalence of ocular findings in AIDS patients

\begin{tabular}{ll}
\hline Ocular manifestation & Frequency (\%) \\
\hline 'AIDS retinopathy' & 64 \\
Cotton wool spots & 12 \\
Intraretinal haemorrhages & \\
Opportunistic ocular infections & 28 \\
CMV retinitis & 4 \\
Herpes zoster ophthalmicus & 0.5 \\
Presumed varicella-zoster retinitis & 0.5 \\
Presumed cryptococcal choroiditis & 1 \\
Toxoplasma gondii retinochoroiditis & 1 \\
Bacterial corneal ulcers & \\
Ocular neoplasms & 1.5 \\
Eyelid Kaposi's sarcoma & 1 \\
Conjunctival Kaposi's sarcoma & \\
Neuro-ophthalmic lesions & 2.5 \\
Optic neuropathy & 1.5 \\
Papilloedema & 4 \\
Cranial nerve palsy or motility disturbance & \\
\hline
\end{tabular}




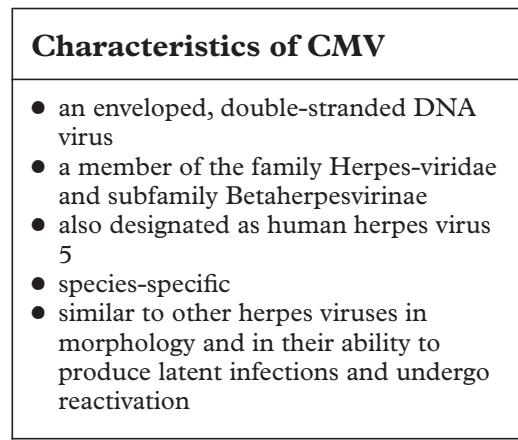

Box 1

\begin{tabular}{l} 
Absolute CD4+ T-lymphocyte \\
(CD4) count \\
\hline normal range: $600-1500$ cells/ $\mu \mathrm{l}$ \\
(varies between laboratories) \\
- correlates with the likelihood of \\
progression to AIDS and death \\
- surrogate marker of stage of HIV \\
infection \\
counts below 200 cells/ $\mu$ l typical in \\
patients with symptomatic advanced \\
HIV disease \\
\hline
\end{tabular}

Box 2

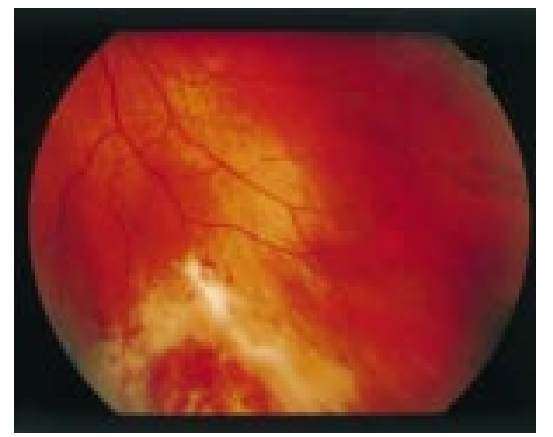

Figure 1 CMV retinitis showing multiple granular-appearing white dots with several areas of retinal haemorrhage and perivasculitis

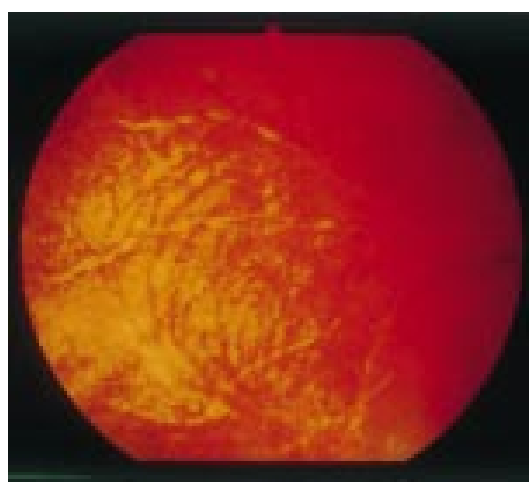

Figure 2 Healed CMV retinitis showing typical chorioretinal atrophy. The choroidal vasculature has become more easily visualised because the retinal pigment epithelium has undergone atrophy. Photograph courtesy of Mr AB Tullo

SIGNS

Untreated CMV retinitis can result in a variety of clinical appearances. Invasion of the retinal cells by the virus causes a full-thickness retinal necrosis, and this appears as multiple granular-appearing white dots with varying amounts of intraretinal haemorrhage (figure 1). If left untreated, these lesions tend to enlarge and coalesce over time. As the retinal tissue loses its capacity to support viral replication, the retina and the underlying pigment epithelium become atrophic, and the choroidal vasculature is therefore more easily visualised (figure 2). Consequently, untreated CMV retinitis typically appears as an advancing edge of active, white retinitis with varying amounts of haemorrhage, which extends from an area of chorioretinal atrophy (figure 3). Associated findings which may also be present include vascular attenuation, perivasculitis (figure 1), mild vitritis and anterior uveitis. Recurrent retinitis despite specific anti-CMV treatment tends to be indolent. Serial fundal photography may help in the detection of slowly extending areas of active retinitis (figures 4 and 5).

RETINAL DETACHMENT

Retinal detachment occurs in at least $20 \%$ of patients with CMV retinitis, and the risk appears to increase with the duration of infection. ${ }^{11}$ Although the full-thickness necrosis of CMV-infected retina is usually replaced by a thin glial sheet, a full-thickness retinal break or an area of multiple breaks may develop. Fluid from the vitreous cavity can then pass through the retinal break(s) and cause the sensory retina to separate from the retinal pigment epithelium, thus producing a rhegmatogenous retinal detachment.

The impact of treatment of CMV retinitis on the risk of retinal detachment remains a matter of debate. It has been suggested by some authors that ganciclovir therapy predisposes a patient to retinal detachment by reducing adhesive scar formation. ${ }^{11}$ It may also hasten the development of retinal detach-

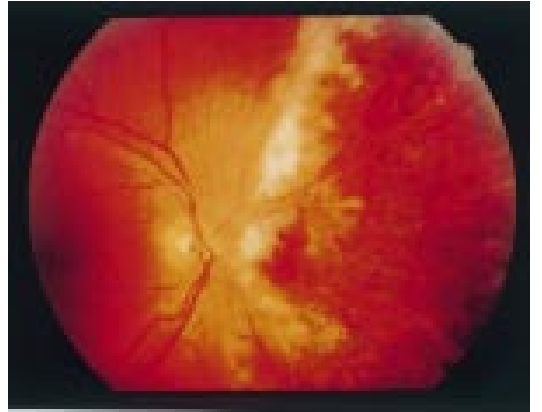

Figure 3 CMV retinitis demonstrating a leading edge of active white retinitis. Progression of the infection has left behind a zone of chorioretinal atrophy in the nasal part of the retina. Photograph courtesy of Mr AB Tullo

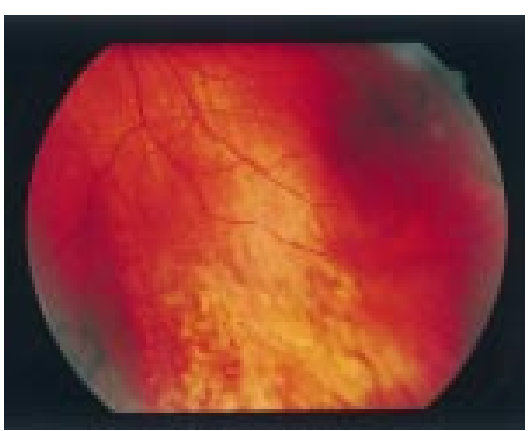

Figure 4 Same patient as in figure 1 one month after commencement of anti-CMV therapy. The whitish retinal infiltrates and perivasculitis have completely resolved 


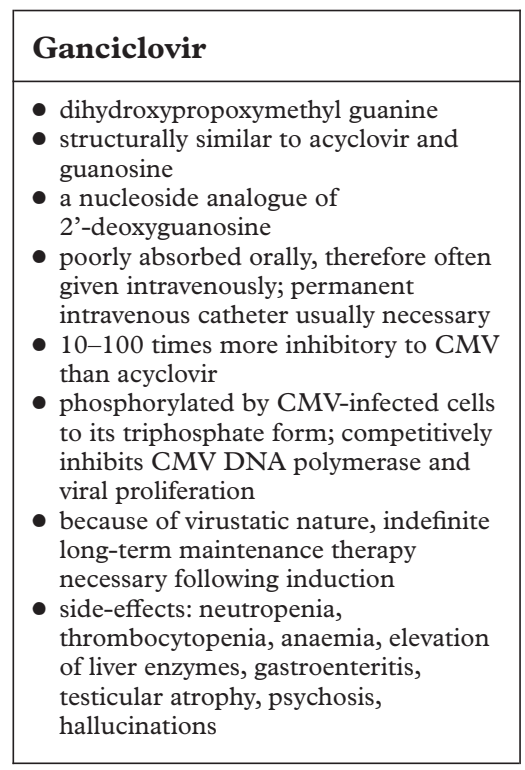

Box 3

\begin{tabular}{|l|}
\hline Foscarnet \\
\hline trisodium phosphonoformate \\
hexahydrate \\
- a pyrophosphate analogue \\
inhibits herpes virus (including CMV) \\
DNA polymerase and HIV-1 reverse \\
transcriptase \\
- side-effects: nephrotoxicity, anaemia, \\
hypocalcaemia with resultant seizures \\
and arrhythmias, hypercalcaemia, \\
hyperphosphataemia, \\
hypophosphataemia, hypokalaemia, \\
hypomagnesaemia, penile and vulvar \\
irritation and ulceration
\end{tabular}

Box 4

\begin{tabular}{|l|}
\hline Cidofovir \\
\hline - nucleotide analogue \\
- long duration of effect \\
- intermittent dosing \\
- side-effects: nephrotoxicity (administer \\
with probenecid and hydration), \\
uveitis, hypotony \\
\hline
\end{tabular}

Box 5

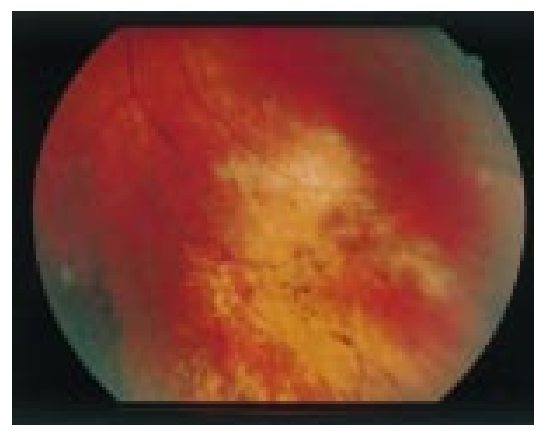

Figure 5 Same patient as in figures 1 and 4 after 4 months of anti-CMV maintenance therapy. Note the recurrence of multiple subtle granular-appearing white dots at the edge of the healed lesion

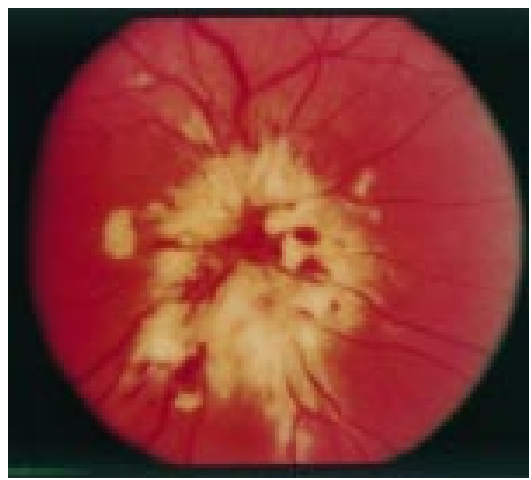

Figure $6 \mathrm{CMV}$ papillitis can usually be diagnosed by examining the retina surrounding the optic disc, as features consistent with the presence of CMV retinitis in the peripapillary area usually suggest the diagnosis. Photograph courtesy of Mr AB Tullo

ment by accelerating the healing phase of the infection, when retinal breaks are known to occur. ${ }^{12}$ However, the reports are not unanimous and one study actually found a reduced risk of retinal detachment with ganciclovir therapy. ${ }^{13}$

Clinically, the retinal detachment may be localised or total, depending on many factors including the location and number of retinal breaks. Visual field defects resulting from regions of CMV retinitis, or a reduction in acuity resulting from involvement of the macula or optic nerve (figure 6) may delay the diagnosis of retinal detachment in these patients.

\section{Diagnosis}

The diagnosis of CMV retinitis is based on the clinical findings. Since the vast majority of AIDS patients have been infected with CMV, the presence of anti-CMV antibodies or the isolation of CMV from other body sites such as blood and urine cultures is insufficient to establish a diagnosis of CMV retinitis. As it is recommended that equivocal lesions should be monitored for progression without treatment, it is essential that physicians be familiar with the clinical features of CMV retinitis.

DIFFERENTIAL DIAGNOSES

The major disorders in the differential diagnosis of CMV retinitis include toxoplasmic retinochoroiditis, varicella-zoster virus retinopathy, herpes simplex virus retinopathy and syphilitic retinitis. It should be remembered, however, that these disorders can occur concurrently with CMV retinitis. In any case of presumed CMV retinitis with atypical features or poor response to therapy, concurrent infections should be considered.

\section{Natural history}

Untreated CMV retinitis usually progresses relentlessly, and ultimately results in irreversible blindness. It also tends to become a bilateral disease. ${ }^{10}$

\section{Treatment}

With the drugs that are currently available to treat CMV retinitis, it is now rare for AIDS patients to die without any vision as a result of this retinal infection. The drugs currently available for treatment of CMV retinitis include ganciclovir, foscarnet and cidofovir, all of which are virustatic (boxes 3-5). They may be given systemically or locally.

\section{SYSTEMIC TREATMENT}

Patients are given an initial 'induction' course of therapy for 14 days, designed to inactivate the CMV and prevent further enlargement of retinal lesions. Induction therapy is followed by 'maintenance' therapy, usually for life, to prevent disease reactivation (box 6). As the drugs are given intravenously, long-term maintenance therapy is problematic in these immunocompromised patients because of the risk of life-threatening sepsis. Furthermore, the presence of an 


\begin{tabular}{|l|}
\hline Systemic treatment \\
\hline Ganciclovir \\
- induction dose: $5 \mathrm{mg} / \mathrm{kg}$ iv 12 -hourly \\
for 2 weeks \\
- maintenance dose: $5 \mathrm{mg} / \mathrm{kg}$ iv daily (or \\
1 g oral tid) \\
Foscarnet \\
- induction dose: $60 \mathrm{mg} / \mathrm{kg}$ iv 8 -hourly \\
or $90 \mathrm{mg} / \mathrm{kg} 12$ hourly for 2 weeks \\
- maintenance dose: $90-120 \mathrm{mg} / \mathrm{kg}$ iv \\
daily with 1 litre normal saline \\
Cidofovir \\
- induction dose: $5 \mathrm{mg} / \mathrm{kg}$ iv once \\
weekly for 2 weeks \\
- maintenance dose: $5 \mathrm{mg} / \mathrm{kg}$ iv once \\
every 2 weeks \\
Combination therapy \\
\hline
\end{tabular}

Box 6

\begin{tabular}{|l|}
\hline Local (intravitreal) therapy \\
\hline Ganciclovir \\
- $200 \mu \mathrm{g}$ to $2 \mathrm{mg}$ dose \\
- induction: $2-3$ times/week for $2-3$ \\
weeks \\
- maintenance: weekly \\
Foscarnet \\
- $2400 \mu \mathrm{g}$ dose \\
- induction: $2-3$ times/week for $2-3$ \\
weeks \\
- maintenance: weekly \\
Cidofovir \\
- $20 \mu \mathrm{g}$ dose \\
- effective for 4-6 weeks after single \\
injection \\
Ganciclovir intra-ocular implant \\
- surgically implanted \\
- lasts 6-8 months \\
\hline
\end{tabular}

Box 7 indwelling catheter and the time required to infuse these medications reduce the patient's quality of life. Although oral ganciclovir obviates some of the problems associated with intravenous therapy, it has poor bioavailability and is given as maintenance therapy only. It is also less efficacious than intravenous ganciclovir.

On cessation of therapy, the average time to progression of retinitis is $2-3$ weeks. ${ }^{10}$ In a recent randomised clinical trial, the median time to progression of disease was 47 days for patients treated with ganciclovir and 53 days for patients treated with foscarnet. ${ }^{14}$ In patients not on highly active anti-retroviral therapy (HAART), the disease will reactivate and progress in nearly all patients with the current anti-CMV treatment regimens, if they survive long enough. This may be due to a combination of factors including development of resistant CMV strains, a deteriorating immune status of the patients or inadequate drug dosing. However, in most cases, the first reactivation of CMV retinitis can be brought under control by administering induction-level doses of the same drug that is being used for maintenance.

Acyclovir and zidovudine (azidothymidine) in general are not effective in treating established CMV retinitis, although a few cases of CMV retinitis have been reported to resolve on zidovudine therapy, possibly as a result of temporarily improved immunocompetence. ${ }^{15}$

\section{LOCAL (INTRAVITREAL) THERAPY}

Direct injection of ganciclovir into the vitreous cavity has been used as an alternative to systemic treatment. ${ }^{16-20}$ It has the advantage of achieving therapeutic levels by circumventing the inefficiency of ganciclovir in crossing the blood-retina barrier. Moreover, the systemic exposure to ganciclovir following clearance from the eye is extremely small, avoiding associated adverse systemic effects. It is particularly suitable in patients who cannot take intravenous ganciclovir due to myelosuppression and in patients who are receiving zidovudine, which may preclude the use of intravenous ganciclovir due to the added myelosuppressive effect. In those cases that fail to respond in spite of aggressive systemic treatment, adjunctive intravitreal treatment should also be considered. Intravitreal foscarnet ${ }^{21}$ and intravitreal cidofovir ${ }^{22}$ have also been used with success in controlling CMV retinitis (box 7).

The fact that local therapy does not treat the fellow eye or non-ocular disease has been viewed as a major disadvantage. All patients with untreated CMV retinitis have evidence of non-ocular tissue-invasive CMV infections at autopsy, although not all of these infections will cause clinically apparent disease. A number of potential complications are associated with intravitreal injections. These include infectious endophthalmitis, an increased rate of retinal detachment, increased intra-ocular pressure at the time of injection, vitreous haemorrhage and retinal toxicity. Intravitreal cidofovir is also associated with iritis and hypotony.

A sustained-release ganciclovir implant has been used for intravitreal implantation with the goal of achieving a longer therapeutic effect and better control of CMV retinitis. ${ }^{23}$ The cumulative data indicate that the ganciclovir implant lengthens the period of disease-free time 2-4-fold compared to conventional intravenous therapy. ${ }^{24} 25$

TREATMENT OF RETINAL DETACHMENT

The decision to repair any retinal detachment is determined by a careful analysis of the potential risks and complications of the operation contrasted with the likelihood of achieving a significant visual benefit. In a patient with AIDS and CMV-related retinal detachment, the determination of benefit is not usually clear-cut and the decision to operate requires special consideration of such factors as the overall clinical status and life expectancy of the patient, the status of the fellow eye, and the wishes of the patient. As a result of improved survival with better anti-retroviral treatment, there is a trend in recent years for ophthalmologists to be more aggressive in treating CMV-related retinal detachment, even if only one eye is affected. The treatment goal has gradually evolved from keeping one eye seeing until the patient passes away (previously after 3-4 months) to preserving good vision in both eyes indefinitely.

The modalities of treatment of retinal detachment include laser photocoagulation to wall off the detachment or retinal breaks and scleral buckling. However, most cases require treatment by pars plana vitrectomy combined with intravitreal gas or, more usually, silicone oil injection.

\section{Changing pattern of CMV retinitis}

In the past few years, a dramatic improvement in the prognosis for HIV-infected patients has been achieved with the strategy involving a combination of 
Table 2 Ophthalmic screening of HIV patients

\begin{tabular}{ll}
\hline CD4 count (cells/ $\mu l)$ & Screening interval (months) \\
\hline$\leqslant 50$ & $2-3$ months \\
$51-250$ & $3-4$ months \\
$250-500$ & $5-6$ months \\
\hline
\end{tabular}

anti-retroviral drugs to bring about a profound and durable suppression of viral replication. ${ }^{26}$ HAART regimens consisting of an HIV protease inhibitor combined with one or two dideoxynucleoside agents (reverse transcriptase inhibitors) dramatically increase absolute CD4 counts, reduce HIV viral load and improve survival, even in patients with very low CD 4 counts. ${ }^{27}$

The incidence of CMV retinitis has declined dramatically among patients maintained on HAART. Prior to the introduction of HAART, the natural history of untreated CMV retinitis was relentless progression of full thickness retinal necrosis leading to blindness. It is now becoming clear that some patients with CMV retinitis who respond to HAART in terms of elevated CD4 count and reduced HIV viral load undergo no reactivation of their retinitis despite having no specific anti-CMV therapy. ${ }^{28}{ }^{29}$ However, the factors underlying this improved immunity are not entirely clear. Most cases of HAART-induced spontaneous and sustained resolution of CMV retinitis had elevated CD4 counts. However, sustained resolution of CMV retinitis in a patient with a persistently low CD4 count has been reported. ${ }^{30}$ In some patients with healed CMV retinitis and sustained HAART-induced CD4 count elevation, close ophthalmologic observation and $\mathrm{CD} 4$ count monitoring may be substituted for anti-CMV therapy.

One of the features that has characterised CMV retinitis in patients with AIDS is a scarcity of inflammation in the anterior chamber and vitreous humour. ${ }^{31}$ Indeed, the presence of marked vitreous inflammation can help to differentiate CMV retinitis from other causes of retinitis in patients with AIDS, such as toxoplasmic retinochoroiditis. During treatment with HAART, a transient vitreous inflammatory reaction in patients with AIDS and CMV retinitis has been reported. ${ }^{32}$ This inflammation reflects an improved immune response against $\mathrm{CMV}$, and may be associated with cystoid macular oedema and epiretinal membrane formation. This new syndrome has been named immune recovery vitritis. It responds to either systemic or repository corticosteroid treatment, without reactivation of the CMV retinitis. ${ }^{33}$

\section{Conclusion}

As anti-retroviral treatments improve, we are witnessing a change in the pattern of CMV retinitis in HIV disease. ${ }^{34}$ Although the incidence of CMV retinitis has declined with the introduction of HAART, CMV retinitis remains a threat to the vision in these patients. Physicians should therefore know when to conduct ophthalmic screening for patients with HIV disease (table 2) and be familiar with the clinical features of CMV retinitis and its recurrence.

1 Holland GN, Tufail A, Jordan MC. Cytomegalovirus diseases. In: Pepose JS, Holland GN, Williams KR, eds, Ocular infection and immunity. St Louis: Mosby, 1996; pp 1088-128.

2 Ai E. Infectious viral and opportunistic retinitis. In: Freeman WR, ed. Practical atlas of retinal disease and therapy, 2nd edn. Philadelphia: Lippincott-Raven, 1998; pp 101-18.

3 Holland GN, Gottlieb MS, Yee RD, Schanker

HM, Pettit TH. Ocular disorders associated $\mathrm{HM}$, Pettit TH. Ocular disorders associated
with a new severe acquired cellular immunowith a new severe acquired chellular immuno393-402.

4 Friedman AH, Freeman WR, Orellana J, Kraushar MF, Starr MB, Luntz MH. Cytomegalovirus retinitis and immunodeficiency in homosexual males. Lancet 1982;1:958.

5 Freeman WR, Lerner CW, Mines JA, et al. A prospective study of the ophthalmologic findings in the acquired immune deficiency syndrome. Am f Ophthalmol 1984;97:133-42.

6 Jabs DA, Green WR, Fox R, Polk BF, Bartlett JG. Ocular manifestations of acquired immune deficiency syndrome. Ophthalmology 1989;96: 1092-9.

7 Kuppermann BD, Petty JG, Richman DD, et al. Correlation between CD4+ counts and prevalence of cytomegalovirus retinitis and human immunodeficiency virus-related noninfectious immunodeficiency virus-related noninfectious
retinal vasculopathy in patients with acquired immunodeficiency syndrome. Am f Ophthalmol 1993;115:575-82

8 Freeman WR, Henderly DE, Lipson BK, Rao NA, Levine AM. Retinopathy before the diagnosis of AIDS. Ann Ophthalmol 1989;21:46874

9 Sison RF, Holland GN, MacArthur LJ, Wheeler NC, Gottlieb MS. Cytomegalovirus retinopathy as the initial manifestation of the acquired immunodeficiency syndrome. Am 7 Ophthalmol 1991;112:243-9.

10 Jabs DA, Enger C, Bartlett JG. Cytomegalovirus retinitis and acquired immunodeficiency synretinitis and acquired immunodeficiency

11 Freeman WR, Henderly DE, Wan WL, et al. Prevalence, pathophysiology, and treatment of rhegmatogenous retinal detachment in treated cytomegalovirus retinitis. Am $\mathcal{f}$ Ophthalmol 1987;103:527-36.

12 Gross JG, Bozzette SA, Mathews WC, et al. Longitudinal study of cytomegalovirus retinitis in acquired immune deficiency syndrome. $O p h-$ thalmology 1990;97:681-6.

13 Jabs DA, Enger C, Haller J, De BS. Retinal detachments in patients with cytomegalovirus retinitis. Arch Ophthalmol 1991;109:794-9.

14 Studies of Ocular Complications of AIDS Research Group in collaboration with the AIDS Clinical Trials Group. Mortality in patients with Clinical Trials Group. Mortality in patients with
the acquired immunodeficiency syndrome the acquired immunodeficiency syndrome
treated with either foscarnet or ganciclovir for cytomegalovirus retinitis. $N$ Engl 7 Med 1992; 326:213-20

15 Guyer DR, Jabs DA, Brant AM, Beschorner WE, Green WR. Regression of cytomegalovirus retinitis with zidovudine. A clinicopathologic correlation. Arch Ophthalmol 1989;107:868-74.

16 Cochereau MI, LeHoang P, Lautier FM, et al. Efficacy and tolerance of intravitreal ganciclovir in cytomegalovirus retinitis in acquired immune in cytomegalovirus retinitis in acquired immune deficiency

17 Heinemann $\mathrm{MH}$. Long-term intravitreal ganciclovir therapy for cytomegalovirus retinopathy. Arch Ophthalmol 1989;107:1767-72.

18 Henry K, Cantrill H, Fletcher C, Chinnock BJ, Balfour-HHJ. Use of intravitreal ganciclovir (dihydroxy propoxymethyl guanine) for cytomegalovirus retinitis in a patient with AIDS. $A m \mathcal{F}$ Ophthalmol 1987;103:17-23.

19 Ussery FM, Gibson SR, Conklin RH, Piot DF, Stool EW, Conklin AJ. Intravitreal ganciclovir in the treatment of AIDS-associated cytomegalovirus retinitis. Ophthalmology 1988;95:640-8.

20 Buchi ER, Fitting PL, Michel AE. Long-term intravitreal ganciclovir for cytomegalovirus retinitis in a patient with AIDS. Case report. Arch Ophthalmol 1988;106:1349-50.

21 Diaz LM, Chipont E, Sanchez S, Espana E, Navea A, Menezo JL. Intravitreal foscarnet for cytomegalovirus retinitis in a patient with 
acquired immunodeficiency syndrome. $A m \mathcal{F}$ Ophthalmol 1992;114:742-7.

22 Kirsch LS, Arevalo JF, Chavez-de 1P, Munguia D, De CE, Freeman WR. Intravitreal cidofovi (HPMPC) treatment of cytomegalovirus retinitis in patients with acquired immune deficiency syndrome. Ophthalmology 1995;102:533-42.

23 Smith TJ, Pearson PA, Blandford DL, et al. Intravitreal sustained-release ganciclovir. Arch Ophthalmol 1992;110:255-8.

24 Martin DF, Parks DJ, Mellow SD, et al. Treatment of cytomegalovirus retinitis with an intraocular sustained-release ganciclovir implant. A randomized controlled clinical trial Arch Ophthalmol 1994;112:1531-9.

25 Anand R, Nightingale SD, Fish RH, Smith TJ, Ashton P. Control of cytomegalovirus retinitis using sustained release of intraocular ganciclovir. Arch Ophthalmol 1993;111:223-7.
26 Ash S. Combination HIV therapy and opportunistic infections of the eye in people with AIDS. Br f Ophthalmol 1998;82:981-2.

27 Jacobson MA, Zegans M, Pavan PR, et al. Cytomegalovirus retinitis after initiation of highly active antiretroviral therapy. Lancet 1997; 349:1443-5.

28 Whitcup SM, Cunningham ETJ, Polis MA Fortin E. Spontaneous and sustained resolution of CMV retinitis in patients receiving highly of CMV retinitis in patients receiving highly active antiretrovir

29 Reed JB, Schwab IR, Gordon J, Morse LS Regression of cytomegalovirus retinitis associated with protease-inhibitor treatment in patients with AIDS. Am f Ophthalmol 1997;124: 199-205.

30 Nolan W, Mitchell S. Do all patients with CMV retinitis require life long anti-CMV therapy? $\mathrm{Br}$ 7 Ophthalmol 1998;28:844-5.
31 Palestine AG, Rodrigues MM, Macher AM, et al. Ophthalmic involvement in acquired mmunodeficiency syndrome. Ophthalmology 1984:91:1092-9.

32 Zegans ME, Walton RC, Holland GN, O'Donnell JJ, Jacobson MA, Margolis TP. Transient vitreous inflammatory reactions associated with combination antiretroviral therapy in patients with AIDS and cytomegalovirus retinitis. Am f Ophthalmol 1998;125:292-300.

33 Karavellas MP, Lowder CY, Macdonald JC, Torriani FJ, Freeman WR. Immune recovery vitritis in AIDS: natural history, long-term treatment results, and associated factors of a new syndrome (Abstract). Final Programme, Annual Meeting, American Academy of Ophthalmology, New Orleans, 1998; 138.

34 Nussenbatt RB, Lane HC. Human immunodeficiency virus disease: c. Human immunodeficiency virus disease. changing patterns of 1998;125:374-82.

\section{West Sussex History of Medicine Society}

On Saturday mornings 9, 16, 23 October and 13, 27 November 1999 there will be a History of Medicine Course held at the Medical Education Centre, St Richard's Hospital, Chichester, from $10.00 \mathrm{~h}$ to midday.

The course is constructed as an introduction to the History of Medicine Diploma of The Society of Apothecaries, and will include historical method, sources, local medical history, Art in medical history, and the use of primary source material. Speakers are nationally recognised experts.

The course is open to all medical practitioners, students and those interested in healthcare, but numbers are limited. The fee is $£ 35.00$ for the course or $£ 7.50$ per session and further information may be obtained from Rebecca Quick at Chichester Medical Education Centre, St Richard's Hospital, Chichester, PO19 4SE, or tel 01243831509. 